\title{
STUDY OF DISTRIBUTION OF ESCHARS IN PAEDIATRIC SCRUB TYPHUS PATIENTS AT A TERTIARY CARE HOSPITAL
}

\author{
D. Ramaganeshan'1, A. Deepak Kumar'2, P. Ramu³, J. Ravi Teja ${ }^{4}$ \\ ${ }_{1}^{1}$ Associate Professor, Department of Paediatrics, Andhra Medical College, King George Hospital, Visakhapatnam. \\ ${ }^{2}$ Assistant Professor, Department of Paediatrics, Andhra Medical College, King George Hospital, Visakhapatnam. \\ ${ }^{3}$ Assistant Professor, Department of Paediatrics, Andhra Medical College, King George Hospital, Visakhapatnam. \\ 4Junior Resident, Department of Paediatrics, Andhra Medical College, King George Hospital, Visakhapatnam.
}

\section{ABSTRACT}

\section{BACKGROUND}

Scrub typhus is caused by an organism related to Rickettsia species Orientia tsutsugamushi. It causes a disseminated vasculitis and perivascular inflammatory lesions whose net result is significant vascular leakage and end organ injury, especially brain and lungs. Eschar is the site of inoculation which is painless, non-pruritic and is a useful indicator of the disease. In our study, we included the distribution of eschar in paediatric scrub typhus patients.

\section{MATERIAL AND METHODS}

This study was conducted at a tertiary care teaching hospital between June 2013 and November 2015.

\section{AIM OF THE STUDY}

The study was done with the aim of studying distribution of eschar on paediatric patients less than 12 years' age group with presence of eschar and who were confirmed to have scrub typhus with a positive one-step scrub typhus antibody test (SD-BIOLINE tsutsugamushi test).

\section{RESULTS}

A total of 72 cases with eschar were included in the study. Commonest site of eschar in our study was axilla followed by groin. Other common sites of eschar included head and neck and chest.

\section{CONCLUSIONS}

Detection of eschar helps clinically to distinguish scrub typhus from other acute febrile illnesses. Knowledge of common sites of eschar would be useful for early clinical diagnosis of Scrub typhus, especially in endemic areas.

\section{KEYWORDS}

Scrub Typhus, Eschar, Orientia Tsutsugamushi, Distribution, Paediatric, One Step Scrub Typhus Antibody Test.

HOW TO CITE THIS ARTICLE: Ramaganeshan D, Kumar AD, Ramu P, et al. Study of distribution of eschars in paediatric scrub typhus patients at a tertiary care hospital. J. Evolution Med. Dent. Sci. 2016;5(57):3960-3963, DOI: 10.14260/jemds/2016/904

\section{INTRODUCTION}

Scrub typhus is an important cause of acute febrile illness in South and East Asia and the Pacific. The causative agent is distinct from but related to Rickettsia species, i.e. Orientia tsutsugamushi. 0 . tsutsugamushi is transmitted via bite of a larval stage (Chigger) of a trombiculid mite (Leptotrombidium), which serves as both vector and reservoir. ${ }^{1}$ Rickettsial infections are re-emerging and are prevalent throughout the world. In India they are reported from Maharashtra, Tamilnadu, Karnataka, Kerala, Jammu and Kashmir, Uttaranchal, Himachal Pradesh, Rajasthan, Assam and West Bengal.2 Scrub typhus has been increasingly reported from almost all parts of the country in the recent years.

Financial or Other, Competing Interest: None.

Submission 10-06-2016, Peer Review 05-07-2016,

Acceptance 11-07-2016, Published 18-07-2016.

Corresponding Author:

Dr. P. Ramu,

Raja Sagi Residency, FF-3,

Door No.: 14-1-122/13,

Nowroji Road, Maharanipeta,

Visakhapatnam-530002,

Andhra Pradesh.

E-mail: drpramu73@gmail.com

DOI: $10.14260 /$ jemds/2016/904
Scrub typhus can be mild or severe in children. A painless papule occurs at the bite site prior to other disease symptoms that later ulcerates and transforms into a black crust or eschar in a variable proportion of patients, but is a useful indicator of the disease. A single painless eschar with an erythematous rim at the site of chigger bite is seen in $7-68 \%$ of cases. ${ }^{1,2}$ Hence, we studied the distribution of eschars in paediatric Scrub typhus patients.

\section{MATERIAL AND METHODS}

This study was conducted at King George Hospital, Visakhapatnam, a tertiary care teaching hospital between June 2013 and November 2015 with an aim of studying the distribution of eschar in paediatric patients of less than 12 years confirmed to have Scrub typhus with a positive one-step scrub typhus antibody test (SD-BIOLINE tsutsugamushi test) and presence of eschar.

\section{RESULTS}

During the study period, out of 93 paediatric patients less than 12 years who are positive for scrub typhus antibody one-step - SD BIOLINE tsutsugamushi test, a total of 72 patients had an eschar. All cases had single eschar. The distribution of eschars over the body of the patients in our study were shown in the Table 1. Some of our patients with eschar were shown in the 
Figure 1, 2, 3, 4, 5, 6, 7, 8, 9 and 10. In our study, eschar was found in axillary region - 24 patients (33.33\%), groin - 16 patients $(22.22 \%)$, head and neck - 8 patients $(11.11 \%)$, chest - 6 patients $(8.33 \%)$, thighs -6 patients $(8.33 \%)$, abdomen -5 patients $(6.95 \%)$, arms -3 patients $(4.17 \%)$, back -2 patients $(2.78 \%)$ and legs - 2 patients $(2.78 \%)$. In our study, the commonest site of eschar was axilla followed by groin and head and neck region.

\begin{tabular}{|c|c|c|}
\hline $\begin{array}{c}\text { Site of } \\
\text { Eschar }\end{array}$ & $\begin{array}{c}\text { Number of Patients } \\
\text { (<12 years) }\end{array}$ & $\begin{array}{c}\text { Percentage } \\
\mathbf{( \% )} \\
(\mathbf{n = 7 2})\end{array}$ \\
\hline $\begin{array}{c}\text { Head \& } \\
\text { Neck }\end{array}$ & 8 & 11.11 \\
\hline Axilla & 24 & 33.33 \\
\hline Arms & 3 & 4.17 \\
\hline Chest & 6 & 8.33 \\
\hline Back & 2 & 2.78 \\
\hline Abdomen & 5 & 6.95 \\
\hline Groin & 6 & 22.22 \\
\hline Thighs & 2 & 8.33 \\
\hline Legs & Table 1: Distribution of Eschars (Present Study) \\
\hline \multicolumn{2}{|c|}{} \\
\hline
\end{tabular}

A total of 72 cases with eschar turned positive for one-step scrub typhus antibody test were included in the study. Commonest site of eschar was axilla followed by groin. Other common sites of eschar included head and neck and chest.

\begin{tabular}{|c|c|c|c|c|}
\hline & \multicolumn{2}{|c|}{$\begin{array}{c}\text { Bahubali D Gane Study } \\
\text { (2011-2015). }\end{array}$} & \multicolumn{2}{c|}{$\begin{array}{c}\text { Present Study } \\
\mathbf{( 2 0 1 3 - 2 0 1 5 )}\end{array}$} \\
\hline $\begin{array}{c}\text { Site of } \\
\text { Eschar }\end{array}$ & $\begin{array}{c}\text { No. of } \\
\text { Patients } \\
\text { (<18 years) }\end{array}$ & $\begin{array}{c}\text { (\%) } \\
\text { (n=52) }\end{array}$ & $\begin{array}{c}\text { No. of } \\
\text { Patients } \\
\text { (<12 years) }\end{array}$ & $\begin{array}{c}(\mathbf{\%}) \\
(\mathbf{n = 7 2})\end{array}$ \\
\hline $\begin{array}{c}\text { Head \& } \\
\text { Neck }\end{array}$ & 2 & 3.84 & 8 & 11.11 \\
\hline Axilla & 15 & 28.84 & 24 & 33.33 \\
\hline Arms & 1 & 1.92 & 3 & 4.17 \\
\hline Chest & 5 & 9.61 & 6 & 8.33 \\
\hline Back & 3 & 5.76 & 2 & 2.78 \\
\hline Abdomen & 7 & 13.46 & 5 & 6.95 \\
\hline Groin & 14 & 26.92 & 16 & 22.22 \\
\hline Thighs & 2 & 3.84 & 6 & 8.33 \\
\hline Legs & 3 & 5.76 & 2 & 2.78 \\
\hline \multicolumn{2}{|c|}{ Table 2: Comparison of Distribution of Eschars } \\
\hline
\end{tabular}

Our study had good correlation with Bahubali D Gane study (2011-2015). ${ }^{3}$ regarding the common sites of eschar, i.e. axilla and groin regions and other less common sites also.

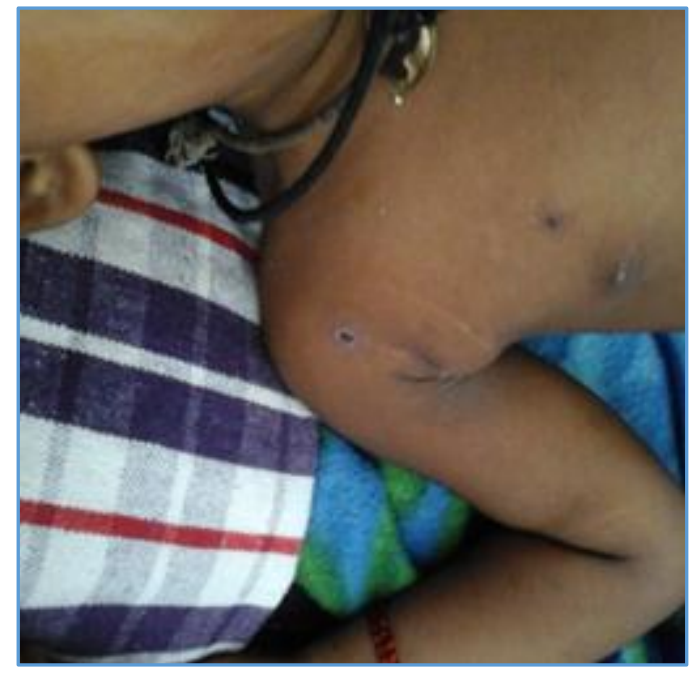

Fig. 1: Eschar at Axillary Region

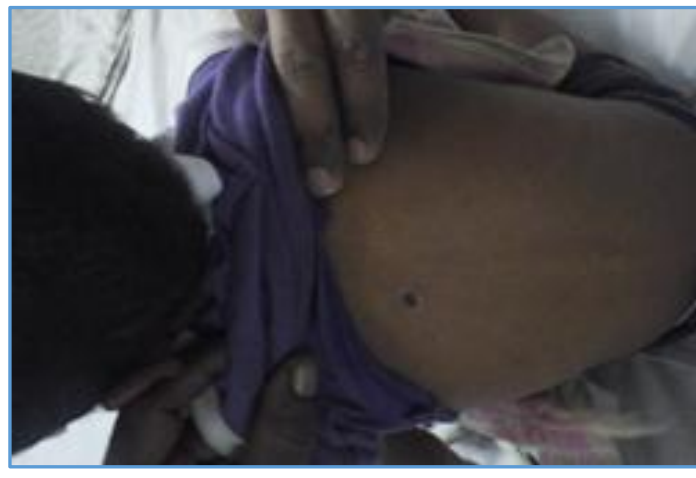

Fig. 2: Eschar on Back

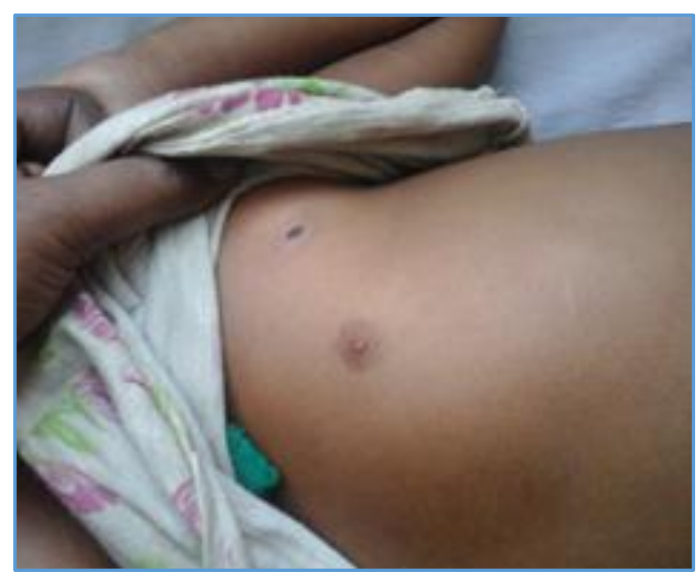

Fig. 3: Eschar at Axilla

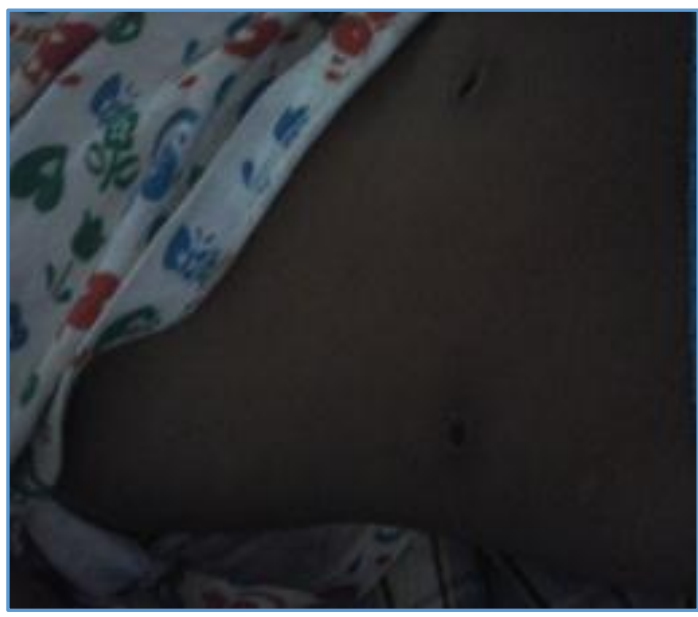

Fig. 4: Eschar at Lower Abdomen

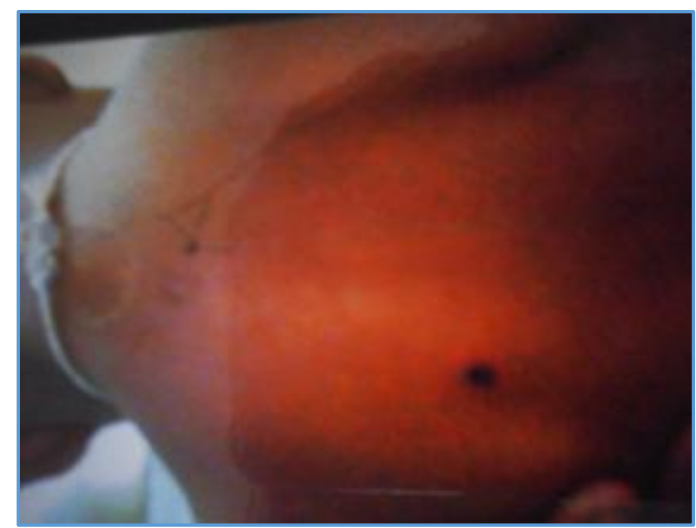

Fig. 5: Eschar over Back 


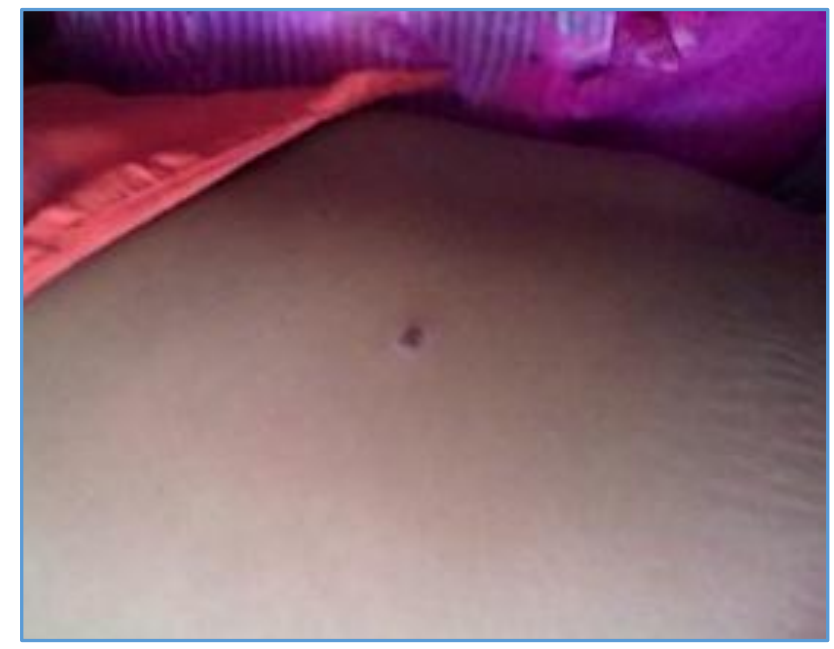

Fig. 6: Eschar at Upper Abdomen

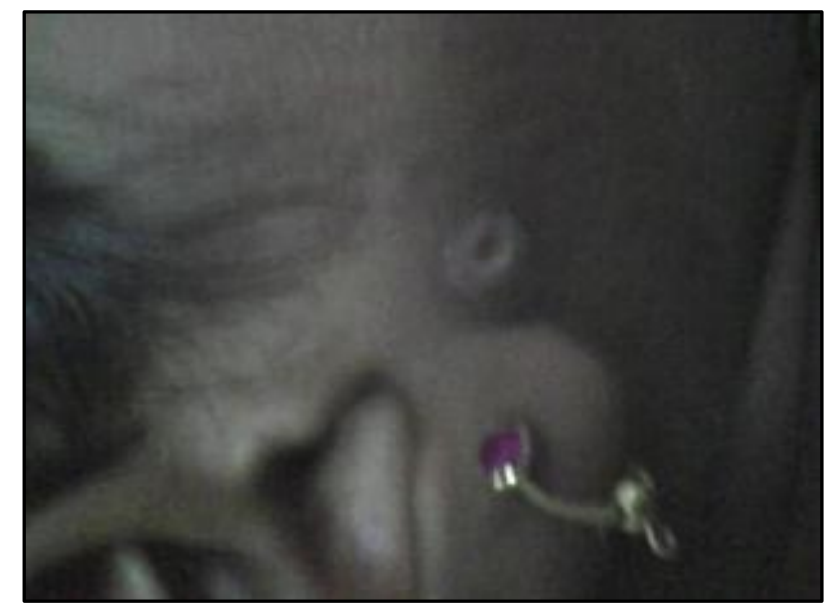

Fig. 7: Eschar over Face Pre-Auricular Region

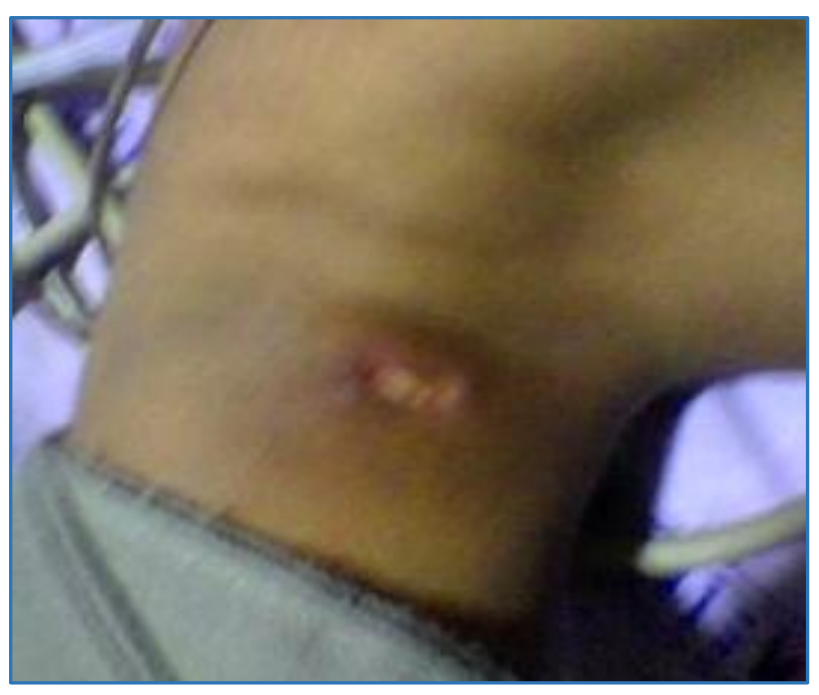

Fig. 8: Eschar at Axilla

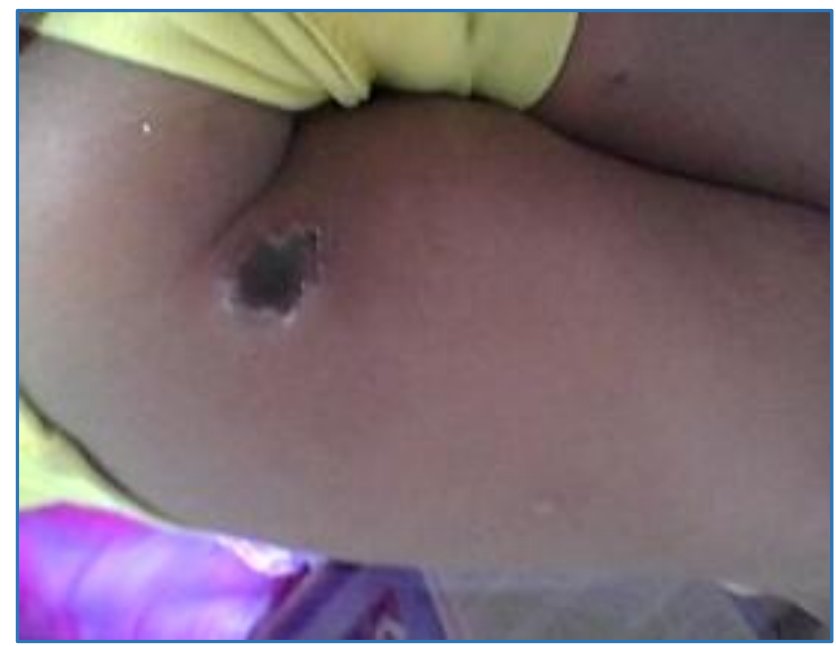

Fig. 9: Eschar at Gluteal Region

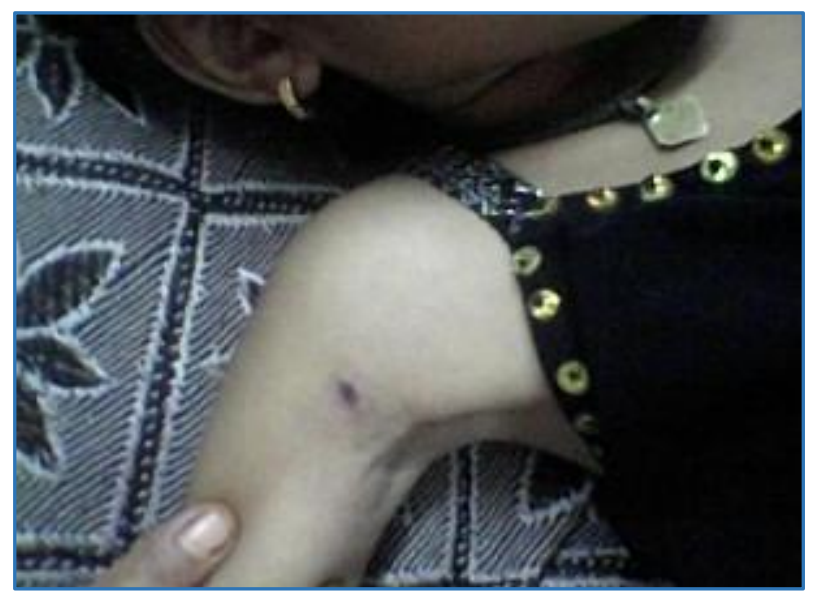

Fig. 10: Eschar at Axilla

\section{DISTRIBUTION OF ESCHARS IN OUR STUDY IN} PERCENTAGES (\%)

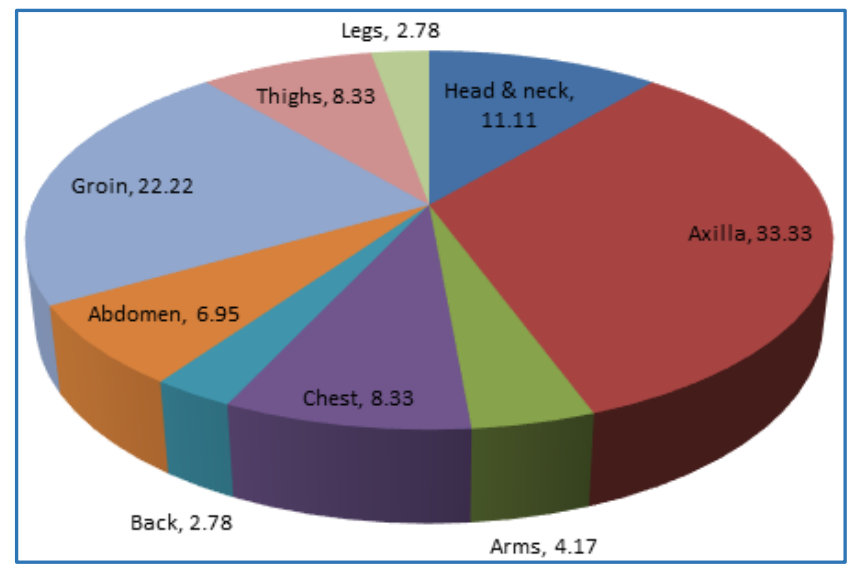

Chart 1 


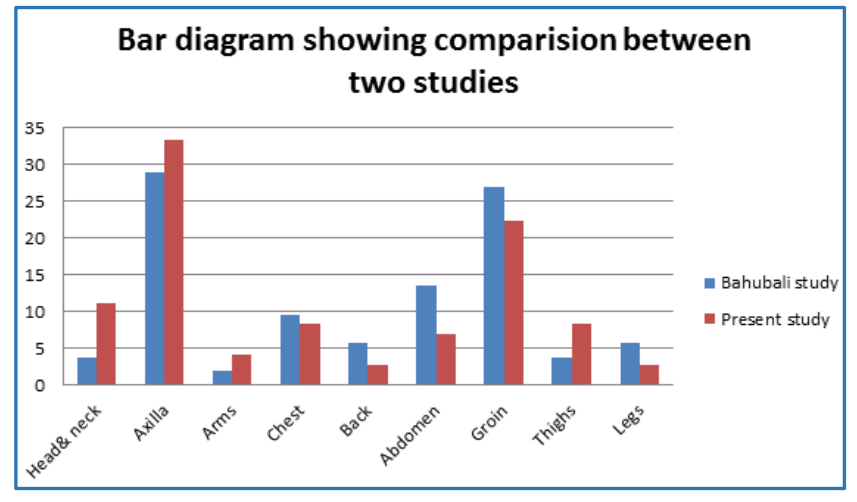

Chart 2

\section{DISCUSSION}

A single painless eschar with an erythematous rim at site of the chigger bite is seen in 7-68\% of cases, which is a typical feature of scrub typhus and helps in diagnosis of scrub typhus. Areas where skin folds are found and moist areas should be examined for the presence of eschar. An eschar is formed when an infected chigger bites the skin while feeding on human skin. It bites in warm, damp areas like axilla, groin. The organisms multiply at the site of inoculation and form papule, which ulcerates and becomes necrotic and forms a typical black eschar with or without regional lymphadenopathy. An eschar measures around 0.5-20 mm. Eschar may resolve completely in 3-4 weeks with no sequelae or it may cause hyperpigmentation or scarring. Since eschar is a painless lesion, patients may be unaware of it. Humans are accidental hosts. Scrub typhus can be mild or severe in children. Scrub typhus presents as a systemic vasculitis like infection with varied systemic manifestations and complications which include jaundice, meningoencephalitis, myocarditis, interstitial pneumonia leading to ARDS and renal failure. The differential diagnosis includes fever of unknown origin, enteric fever, dengue haemorrhagic fever, leptospirosis, malaria, other rickettsioses and infectious mononucleosis. ${ }^{4}$ Diagnosis is confirmed by isolation of organism in culture or serological tests like IgM capture ELISA, which have a retrospective value but are confirmatory. Other diagnostic tests include indirect fluorescent antibody test. Weil-Felix test and immunechromatographic tests, PCR and Anti 0 tsutsugamushi IgM and IgG based rapid diagnostic tests have been developed. 4,5 These tests are usually unavailable in poor tropical areas. In our study, we have used SD-BIOLINE one-step tsutsugamushi antibody test. 6 Scrub typhus is very responsive to treatment such as doxycycline or tetracycline. Azithromycin is a good alternative. Therapy should be continued for a minimum of 5 days and until the patient had been afebrile for 3 days to avoid relapse.

\section{CONCLUSION}

Scrub typhus being an important cause of acute febrile illness and many common febrile illnesses such as malaria, dengue, enteric fever are included in the differential diagnosis list and moreover owing to the potential for severe complications, timely diagnosis and decision to initiate empiric treatment should be based on clinical suspicion and detection of eschar. Therefore, the clinician should be aware of the varied presentations of scrub typhus as well as common sites of eschar. ${ }^{7}$ and a thorough search for the presence of eschar especially axillary, groin, head and neck regions and also other atypical sites in all patients presenting as fever of unknown origin in endemic areas helps to differentiate scrub typhus from other illnesses.

\section{REFERENCES}

1. Kliegman RM, Stanton, St Geme J, et al. Nelson's textbook of paediatrics. Scrub typhus. Chapter- 229. First south Asia edition. Elsevier 2015:1504-1505.

2. Parthasarsthy A, Borker AS, Nair MKC, et al. Parthas fundamentals of paediatrics. $2^{\text {nd }}$ edn. New Delhi, India: Jaypee Brothers 2013:139-140.

3. Gane BD, Narayana P, Hiremath PB. Distribution of eschar in children with scrub typhus. JEMDS 2015;4(69):11953-6.

4. Farrar J, Hotez P, Junghanss T, et al. Mansons tropical diseases. Chapter 22. 23rd edn. Philadelphia: Saunders Ltd 2013:283-285.

5. Blacksell SD, Bryant NJ, Paris JA, et al. Scrub typhus serologic testing with the indirect immunofluorescence method as a diagnostic gold standard: a lack of consensus leads to a lot of confusion. Clin Infect Dis 2007;44(3): 391-401.

6. Jiang J, Marienau KJ, May LA, et al. Laboratory diagnosis of two scrub typhus outbreaks at camp Fuji, Japan in $2000 \& 2001$ by enzyme-linked immunosorbent assay, rapid flow assay \& western blot assay using outer membrane $56 \mathrm{kD}$ recombinant proteins. Am J Trop Med 2003;69(1):60-6.

7. Kim DM, Won KJ, Park CY, et al. Distribution of eschars on body of scrub typhus patients: a prospective study. Am J Trop Med Hyg 2007;76(5):806-9. 